\title{
Covid-19 and Pregnancy: A Scientometric Assessment of Global Publications during 2020-21
}

\author{
Madhu Bansal ${ }^{1, *}$, Jivesh Bansal ${ }^{2}$, BM Gupta $^{3}$, Ashok Kumar ${ }^{4}$ \\ 'Department of Mathematics Library, Panjab University, Chandigarh, INDIA. \\ ${ }^{2}$ Panjab University, AC Joshi Library, Chandigarh, INDIA. \\ ${ }^{3}$ Formerly with CSIR-NISTADS, New Delhi, INDIA. \\ ${ }^{4}$ Indira Gandhi University, Meerpur, Rewari, Haryana, INDIA.
}

\begin{abstract}
Background: Covid-19 pandemic had been a disastrous catastrophe on human race affecting different groups of population differently. Pregnancy is a condition which too has been affected by Covid-19. The present study aims to examine the research productivity of Covid-19 and pregnancy. Methods: Keywords pertaining to "Covid-19" and "Pregnancy" were used in search string in Scopus database for the period 2020-21. Data regarding publications growth, productive countries, authors and institutions, high cited papers and significant keywords was retrieved to analyze results. Results: The search retrieved 2945 global publications for the period 2020-21. The USA, UK and China were the most productive countries (with 28.96\%, $11.27 \%$ and $9.3 \%$ global share) on "Covid-19 and Pregnancy". The 613 organizations and 953 authors participated in global research on the subject, with top 20 most productive organizations and authors contributing $26.38 \%$ and $9.68 \%$ global publication share and $53.64 \%$ and $38.53 \%$ global citation share respectively. Huazhong University of Science and Technology, China, Tongji Medical College, China and Harvard Medical School, USA were the most productive organizations (with 68,64 and 52 publications) and Huazhong University of Science and Technology, China (45.88 and 2.12), Tongji Medical College, China (44.96 and 2.08) and University of Health Sciences, Turkey (22.38 and 1.03) led the world as most impactful organizations in terms of citation impact and relative citation index. A Khalil (23 papers), C. Gyamfi-Bannerman (19 papers) and D. Goffman and I.C.

Poon (17 papers each) were the most productive authors and H. Yang (197.4 and 4.66), I. Feng (105.12 and 2.5) and D.A. Schwartz (74.82 and 1.77) were the most impactful authors. American Journal of Obstetrics and Gynecology (94 papers), International Journal of Obstetrics and Gynecology (85 papers) and European Journal of Obstetrics and Gynecology and Reproductive Biology (66 papers) were the most productive journals in global research on "Covid-19 and Pregnancy". JAMA-Journal of the American Medical Association (45.52), Acta Obstetricia et Gynecologica Scandinavica (34.22) and Ultrasound in Obstetrics and Gynecology (25.95) were leading most impactful journals. The $61(2.07 \%)$ out of 2945 global publications on "Covid-19 and Pregnancy" registered 102 to 1571 citations per paper and they together received 14620 citations averaging 239.67 citations per paper. These 61 publications are assumed as high cited publications and involve 153 authors, 116 organizations and published in 43 journals.

Correspondence

Madhu Bansal,

Department of Mathematics Library, Panjab University, 160014, Chandigarh, INDIA.

Email id: madhu@pu.ac.in

DOI: 10.5530/jyp.2021.13s.82

\section{INTRODUCTION}

Covid-19 pandemic started as 'viral pneumonia' outbreak in Wuhan, China in December 2019. It is caused by severe acute respiratory syndromecoronavirus-2 (SARS-COV-2). It emerged as a serious public health emergency. It spread like a wildfire and assumed as a global pandemic in just few months. ${ }^{1}$ Covid -19 had severely impacted all age groups and especially vulnerable are patients with co-morbidities. Women in pregnancy is considered among high-risk population group. SARS-COV-2 initiates physiological changes in pregnant women which are detrimental to both foetus and mother. ${ }^{2}$ Covid-19 can cause complications in pregnancy like pre-term birth or still birth in few cases. Women in third trimester are more vulnerable to Covid-19 than non-pregnant women. Vertical transmission of Covid-19 from mother to womb is uncommon. In few cases, pregnancy can alter the body's response to viral infections, hence Covid-19 infection can get complicated. Heart diseases in pregnant women predispose women to severe complications in pregnancy. It also increases the risk of perinatal anxiety and depression. It is advisable to have proper antenatal and postnatal care. Strict observation should be done during labour., ${ }^{3,4}$

Covid-19 also predisposes pregnant women to severe complications of pregnancy like eclampsia, hypertension, preterm birth and low birth weight. Covid-19 in pregnant women is found to be associated with increased morbidity and mortality. Women and infants with Covid-19 need constant surveillance to save from long-term health effects. Pregnant women are strictly advised to adhere to Covid-19 preventive strategies. $^{5-7}$

\section{Literature Review}

Numerous bibliometric studies have been conducted on Covid-19 in short span of time. Bibliometric studies have been undertaken on pregnancy and different clinical conditions. Wu, Wang, Yan and Zhao evaluated bibliometrically 630 global records on subclinical thyroidism in pregnancy during 1999 and 2018. The data was retrieved from SCI-Expanded, WoS Core Collection and evaluated the current topics of research of subclinical thyroidism in pregnancy. ${ }^{8}$ Zhang.. [et al.] presented a bibliometric analysis of scientific publications $(n=1938)$ on pregnancy with scarred uterus after cesarean using WoS core collection databases: SSCI and SCI-Expanded for the period 1999 to 2018. ${ }^{9}$ Tantengco, De Jesus, Gampony, Ornos, Vidal Jr, Cagayan ${ }^{10}$ analysed 2009 global publications on molar pregnancy in the last 50 years i.e. from 1970-2020. Data was sourced from the Scopus database and analysed bibliometrically for

This is an open access article distributed under the terms of the Creative Commons Attribution-NonCommercial-ShareAlike 4.0 License, which allows others to remix, tweak, and build upon the work non-commercially, as long as the author is credited and the new creations are licensed under the identical terms. 
publication growth, productive countries, organizations, authors, highcited articles, research hotspots. ${ }^{10}$ Chen, Chen and Cao et al. evaluated bibliometrically 100 high-cited papers on ectopic pregnancy for the period 1965 to 2015. Articles were retrieved from SCI-Expanded database and evaluated according to citations, authorship, journals, originating country and institution. ${ }^{11}$ No bibliometric study is present on "Covid-19 and Pregnancy", hence the present bibliometric study is undertaken.

\section{Methodology}

In the present study, the global publications on "Covid-19 and Pregnancy" were identified and retrieved using a well defined search strategy from the Scopus database (https://www.scopus.com). Two sets of keywords related to "Covid-19" and "Pregnancy" were used in "Keyword" and "Title" field tags and limited the search to 2020-2021 period. The search strategy yielded 2945 global records which were further analyzed by top countries, organizations, authors, subjects and journals.

TITLE ( "Covid 19" or "2019 novel coronavirus" or "coronavirus 2019" or "coronavirus disease 2019" or "2019-novel CoV" or "2019 ncov" or covid 2019 or covid 19 or "corona virus 2019 " or ncov- 2019 or ncov2019 or "nCoV 2019" or 2019-ncov or covid-19 or "Severe acute respiratory syndrome coronavirus 2" or "SARS-CoV-2") or KEY ( "Covid 19" or "2019 novel coronavirus" or "coronavirus 2019" or "coronavirus disease 2019" or "2019-novel CoV" or "2019 ncov" or covid 2019 or covid19 or "corona virus 2019" or ncov-2019 or ncov2019 or "nCoV 2019" or 2019ncov or covid-19 or "Severe acute respiratory syndrome coronavirus 2" or "SARS-CoV-2") and Key (pregnancy)

\section{Analysis and Results Overall Output}

The Scopus database yielded 2945 publications $(2020=1766,2021=1179)$ on the theme "Covid-19 and pregnancy" during 2020-2021. The global publications (2945) received 31342 citations, averaging 10.64 citations per paper. Of the 2945 publications, 420 (14.26\%) resulted from research projects funded by $100+$ funding agencies, received 6294 citations, averaging 14.99 citations per paper. The major funding agencies supporting global research in this area were- U.S. Department of Health and Human Services (118 papers), National Institute of Health (104 articles), National Natural Science Foundation of China (57 articles), Eunice Kennedy Shriver National Institute of Child Health and Human Development (29 papers), European Commission (27 papers), Ministry of Science and Technology of the People's Republic of China (25 papers), National Centre For Advancing Translational Sciences (22 papers), National Institute For Health Research (21 papers), National Institute of Allergy and Infectious Diseases (20 papers), Instituo de Salud Carlos III (19 papers). Of the total publications, articles accounted for the largest publication share $(54.87 \%)$, followed by letters and reviews $(15.72 \%$ and $15.21 \%)$, notes $(7.3 \%)$, editorial $(5.64 \%)$ and the rest contributed less than $1 \%$ of the publications. Majority of the publications (95.14\%) appeared in English language, followed by Spanish (1.87\%), Russian $(0.95 \%)$, Chinese $(0.85 \%)$, French and German $(0.81 \%$ each) and the rest in other languages (from $0.24 \%$ to $0.03 \%$ ).

\section{Top 12 Most Productive Countries}

In all, 114 countries participated in global research on "Covid-19 and Pregnancy", the distribution of which is highly uneven. 75 countries published 1-10 papers each, 32 countries published 11-50 papers each, 5 countries published 51-100 papers each. Only 12 countries published more than 100 papers i.e. $101-853$ papers each. The top 12 countries together contributed $92.43 \%$ global publication share and more than $100 \%$ global citation share. The largest global publication share is contributed by United States (28.96\%), followed by United Kingdom,
China, Italy (11.27\%, 9.3\% and 8.96\%) and the rest by India, Spain, Iran, Australia, Canada, Brazil, France, Turkey (from 5.09\% to 3.46\%). Only two countries registered their citation impact i.e. citations per paper and relative citation index above their group average (12.84 and 1.21): China (37.30 and 3.51) and United States (12.87 and 1.21) (Table 1).

Figure 1 presents the network visualization map of 12 most productive countries generated using VOS Viewer software tool. It depicts United States as the most productive country followed by United Kingdom and China. It also shows the collaborative linkages among the countries.

All the top 12 countries had collaborative linkages in "Covid-19 and Pregnancy" among each other and their total collaborative linkages varied from 49 to 323 and individual country to country linkages varied from 1 to 63 . The largest collaborative linkages $(323,265$ and 188) are depicted by USA, UK and Italy. Among country to country linkages, the largest number of linkages (63) are between USA-U.K., followed USAItaly (48), USA-China (40), etc. (Table 2).

\section{Subject-Wise Distribution of Publications}

2945 publications on "Covid-19 and Pregnancy" are classified in six broad subjects as identified in Scopus database. Medicine accounted for

\section{Table 1: Profile of Top 12 Most Productive Countries Application on} “Covid-19 and Pregnancy" during 2020-21.

\begin{tabular}{clcccccc}
\hline S.No & $\begin{array}{l}\text { Name of the } \\
\text { Country }\end{array}$ & TP & TC & CPP & ICP & \%ICP & RCI \\
\hline 1 & USA & 853 & 10982 & 12.87 & 282 & 33.06 & 1.21 \\
2 & U.K. & 332 & 3175 & 9.56 & 177 & 53.31 & 0.90 \\
3 & China & 274 & 10219 & 37.30 & 82 & 29.93 & 3.51 \\
4 & Italy & 264 & 2871 & 10.88 & 95 & 35.98 & 1.02 \\
5 & India & 150 & 800 & 5.33 & 31 & 20.67 & 0.50 \\
6 & Spain & 138 & 942 & 6.83 & 50 & 36.23 & 0.64 \\
7 & Iran & 137 & 1119 & 8.17 & 43 & 31.39 & 0.77 \\
8 & Australia & 126 & 1094 & 8.68 & 80 & 63.49 & 0.82 \\
9 & Canada & 119 & 1265 & 10.63 & 77 & 64.71 & 1.00 \\
10 & Brazil & 118 & 580 & 4.92 & 41 & 34.75 & 0.46 \\
11 & France & 109 & 1238 & 11.36 & 37 & 33.94 & 1.07 \\
12 & Turkey & 102 & 657 & 6.44 & 16 & 15.69 & 0.61 \\
& Total of 12 & 2722 & 34942 & 12.84 & & & 1.21 \\
& countries & & & & & & \\
\hline & World total & 2945 & 31342 & 10.64 & & & \\
\hline
\end{tabular}

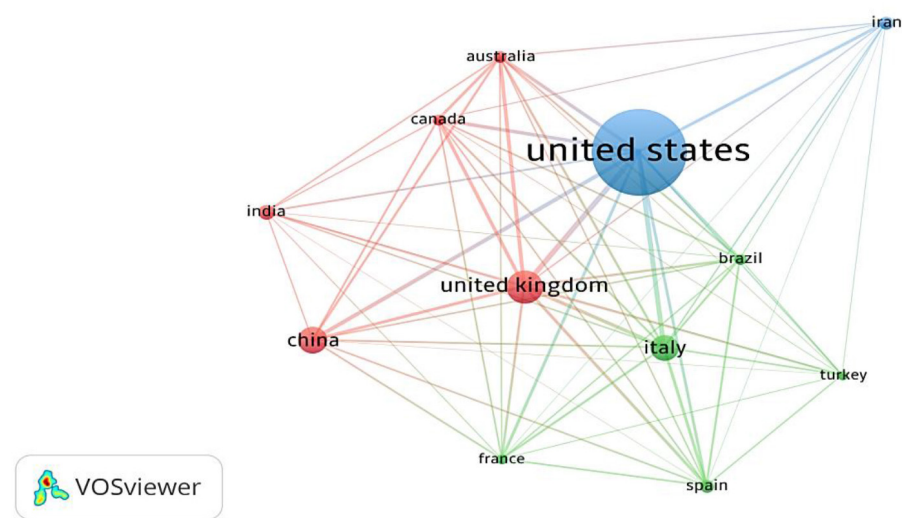

Figure 1: Collaborative Linkages among Top 12 Countries. 
Table 2: Covid-19 and Pregnancy: Collaborative Linkages Among Most Productive Countries 2020-21.

\begin{tabular}{|c|c|c|c|}
\hline S.No & Name of the Country & Collaborative linkages with other countries & $\mathrm{TCL}(\mathrm{NOC})$ \\
\hline 1 & USA & 2(63), 3(40), 4(48), 5(11), 6(20), 7(26), 8(30), 9(34), 10(22), 11(23), 12(6) & $323(11)$ \\
\hline 2 & U.K. & 1(63), 3(25), 4(32), 5(12), 6(23), 7(5), 8(32), 9(29), 10(16), 11(15), 12(13) & 265(11) \\
\hline 3 & China & $1(40), 2(25), 4(10), 5(5), 6(8), 8(15), 9(11), 10(7), 11(8), 12(1)$ & $130(10)$ \\
\hline 4 & Italy & $1(48), 2(32), 3(10), 5(7), 6(22), 7(6), 8(16), 9(12), 10(11), 11(15), 12(9)$ & $188(11)$ \\
\hline 5 & India & 1(11), 2(12), 3(5), 4(7), 6(1), 8(6), 9(5), 10(2), 11(3), 12(1) & $53(10)$ \\
\hline 6 & Spain & $1(20), 2(23), 3(8), 4(22), 5(1), 7(1), 8(6), 9(7), 10(12), 11(7), 12(6)$ & $113(11)$ \\
\hline 7 & Iran & $1(26), 2(5), 4(6), 6(1), 8(6), 9(4), 10(3), 11(1), 12(2)$ & $54(9)$ \\
\hline 8 & Australia & $1(30), 2(32), 3(15), 4(16), 5(6), 6(6), 7(6), 9(23), 10(10), 11(5), 12(2)$ & $151(11)$ \\
\hline 9 & Canada & 1(34), 2(29), 3(11), 4(12), 5(5), 6(7), 7(4), 8(23), 10(9), 11(8), 12(2) & 144(11) \\
\hline 10 & Brazil & 1(22), 2(16), 3(7), 4(11), 5(2), 6(12), 7(3), 8(10), 9(9), 11(6), 12(4) & 107(11) \\
\hline 11 & France & 1(23), 2(15), 3(8), 4(15), 5(3), 6(7), 7(1), 8(5), 9(8), 10(6), 12(3) & $94(11)$ \\
\hline 12 & Turkey & $1(6), 2(13), 3(1), 4(9), 5(1), 6(6), 7(2), 8(2), 9(2), 10(4), 11(3)$ & $49(11)$ \\
\hline
\end{tabular}

TCL (NOC)=Total collaborative linkages (Number of countries)

\begin{tabular}{|c|c|c|c|c|c|}
\hline S.No & Subject & TP & TC & CPP & \%TP \\
\hline 1 & Medicine & 2706 & 29265 & 10.81 & 91.88 \\
\hline 2 & $\begin{array}{l}\text { Biochemistry, Genetics and } \\
\text { Molecular Biology }\end{array}$ & 207 & 1722 & 8.32 & 7.02 \\
\hline 3 & Nursing & 183 & 563 & 3.08 & 6.21 \\
\hline 4 & $\begin{array}{l}\text { Immunology and } \\
\text { Microbiology }\end{array}$ & 163 & 1728 & 10.60 & 5.53 \\
\hline 5 & $\begin{array}{l}\text { Pharmacology, Toxicology } \\
\text { and Pharmaceutics }\end{array}$ & 84 & 832 & 9.90 & $2 . .85$ \\
\hline \multirow[t]{2}{*}{6} & Health Professions & 67 & 2002 & 29.88 & 2.27 \\
\hline & Global Total & 3410 & 36112 & 10.59 & \\
\hline
\end{tabular}

the largest publication share (91.88\%), followed by Biochemistry, Genetics and Molecular Biology (7.03\%), Nursing (6.21\%), Immunology and Microbiology (5.53\%), Pharmacology, Toxicology and Pharmaceutics (2.85\%) and Health Professions (2.28\%). In terms of citation impact, publications on Pharmacology, Toxicology and Pharmaceutics registered the highest citation impact per paper (29.88) and the least by Nursing (3.08) (Table 3).

\section{Significant Keywords}

The 56 significant keywords (with frequency of appearance varying from 93 to 2910) have been identified which gives some broad ideas on the trends of research on the theme "Covid-19 and Pregnancy". Among these keywords, the word 'Coronavirus 2019' had the highest frequency (2910), followed by Pregnancy (2735), Pregnancy Complications (1240), Adults (1102) etc. (Table 4)

Figures 2 and 3 depicts these significant keywords on" Covid-19 and Pregnancy". Higher the thickness of node, the higher the frequency of occurrence. Significant keywords are arranged in four clusters i.e. red, green, blue and purple.

\section{Profile of Top 20 Organizations}

In all 613 organizations participated unevenly in global research on "Covid-19 and Pregnancy": 279 organizations contributed 1-5 papers each, 180 organizations 6-10 papers each, 115 organizations 11-20 papers each and 39 organizations 21-68 papers each. The top 20 organization individually contributed 28 to 68 papers and together they accounted for $26.38 \%$ (777 papers) and $53.64 \%$ (16811 citations) as global publication and global citation share respectively. On further analysis, it was observed that: (i) Six organizations contributed papers higher than their group average (38.85), (ii) Three organizations registered citation per paper and relative citation index above their group average (21.64 and 0.571 ) and (iii) Three organizations registered international collaborative share more than their group average (37.79\%). (Table 5).

\section{Collaboration among Top Organizations}

A collaboration network chart of top 20 organizations on "Covid-19 and Pregnancy" is shown in Figure 4. It shows collaborative linkages among the organizations. The total collaborative linkages of top 20 organizations varied from 1 to 83 and organization to organization collaborative linkages varied from 1 to 64 . The top three organizations with largest collaborative linkages $(83,81$ and 58) were: Huazhong University of Science and Technology, Tongji Medical College and Harvard Medical School (Table 6).

\section{Most Productive Authors}

In all, 953 authors contributed on "Covid-19 and Pregnancy" during 2020-21 and their distribution is highly skewed: 951 authors published 1-5 papers each, 110 authors 6-10 papers each and 22 authors 11-23 papers each. The research productivity of top 20 authors varied from 11 to 23 publications per author. The scientometric profile of top authors on "Covid-19 and Pregnancy" is presented in Table 7. On further analysis, it was observed that: (i) Nine out of top 20 authors published above their group average (14.25): A. Khalil (23 papers), C. Gyamfi-Bannerman (19 papers), D. Goffman and L.C. Poon (17 papers each), D. Jamieson and G. Saccone (16 papers each), D. Baud, A. Berghella and A. Tanacan (15 papers each). (ii) Six out of top 20 authors registered citation per paper and relative citation index above their group average 
Table 4: List of Significant Keywords appearing in Literature on “Covid-19 and Pregnancy" during 2020-21.

\begin{tabular}{|c|c|c|c|c|c|}
\hline S.No. & Name of the Keyword & Frequency & S.No. & Name of the Keyword & Frequency \\
\hline 1 & Coronavirus Disease 2019 & 2910 & 29 & Thorax Radiography & 170 \\
\hline 2 & Pregnancy & 2735 & 30 & Mental Health & 165 \\
\hline 3 & Pregnancy Complication & 1240 & 31 & Adolescents & 161 \\
\hline 4 & Adults & 1102 & 32 & Middle Aged & 158 \\
\hline 5 & Virus Pneumonia & 1036 & 33 & Depression & 155 \\
\hline 6 & Pregnant Women & 957 & 34 & Placenta & 155 \\
\hline 7 & New Born & 730 & 35 & Vaginal Delivery & 154 \\
\hline 8 & Vertical Transmission & 616 & 36 & Preeclampsia & 143 \\
\hline 9 & Virology & 606 & 37 & Pregnancy Diabetes Mellitus & 142 \\
\hline 10 & Pregnancy Outcome & 491 & 38 & Premature Birth & 141 \\
\hline 11 & Cesarean Section & 461 & 39 & Risk Assessment & 140 \\
\hline 12 & Complications & 378 & 40 & Maternal Mortality & 133 \\
\hline 13 & Risk factor & 372 & 41 & Quarantine & 133 \\
\hline 14 & Gestational Age & 324 & 42 & Third Trimester Pregnancy & 129 \\
\hline 15 & Obstetric Delivery & 272 & 43 & Spontaneous Abortion & 126 \\
\hline 16 & Prenatal Care & 267 & 44 & Stillbirth & 115 \\
\hline 17 & Psychology & 244 & 45 & Fetus & 110 \\
\hline 18 & Prematurity & 234 & 46 & Oxygen Saturation & 107 \\
\hline 19 & Breast Feeding & 233 & 47 & Vaccination & 107 \\
\hline 20 & Premature Labor & 232 & 48 & Hypertension & 105 \\
\hline 21 & Epidemiology & 186 & 49 & Myalgia & 104 \\
\hline 22 & Puerperium & 186 & 50 & COVID Testing & 101 \\
\hline 23 & Pathophysiology & 182 & 51 & Laboratory Techniques & 100 \\
\hline 24 & Anxiety & 180 & 52 & Breast Milk & 98 \\
\hline 25 & Child & 180 & 53 & Neonatal Care & 98 \\
\hline 26 & Computer Assisted Tomography & 180 & 54 & Oxygen Therapy & 97 \\
\hline 27 & Hydroxychloroquine & 171 & 55 & Diagnostic Imaging & 95 \\
\hline 28 & Immunology & 171 & 56 & Nasopharyngeal Swab & 93 \\
\hline
\end{tabular}

B vosviewer

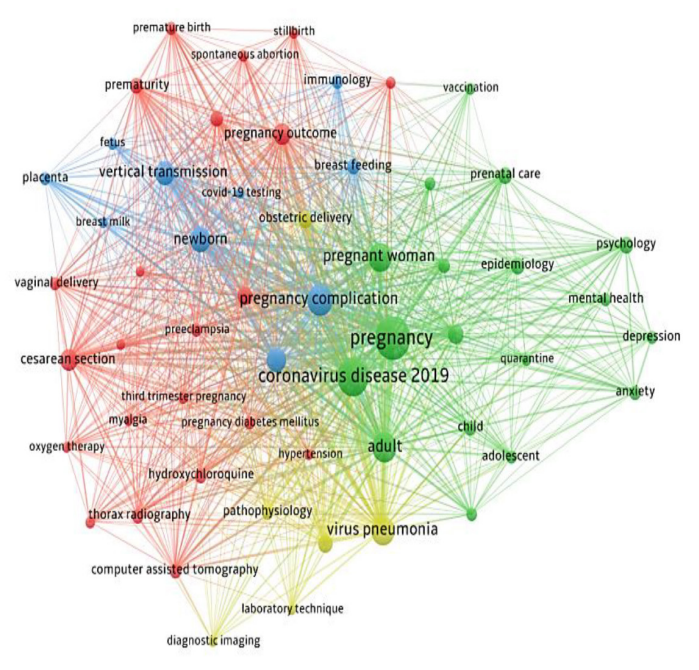

(42.37 and 1.048): H. Yang (197.47 and 4.66), L. Feng (105.82 and 2.5), D.A. Schwartz (74.82 and 1.77), D. Goffman (61.47 and 1.47), L.C. Poon (45.24 and 1.07) and V. Berghella (42.80 and 1.01)[Table 7]. Figure 5 presents the network visualization of top 20 authors on "Covid-19 and Pregnancy". Links depict collaboration among the authors.

\section{Channels of Research Communication}

99.63\% (1616) of research publications on "Covid-19 and Pregnancy" have appeared in journal medium. Of the total 446 journals which reported 1616 articles, 351 published 1-5 papers each, 50 published 6-10 papers each, 39 published 11-50 papers each and 6 published 51-94 papers each. The top 20 most productive journals published 21 to 94 papers each. Together these 20 journals accounted for $29.07 \%$ share. The top 5 most productive journals are: American Journal of Obstetrics and Gynecology (94 papers), International Journal of Gynecology and Obstetrics (85 papers), European Journal of Obstetrics and Gynecology and Reproductive Biology (66 papers) and American Journal of Perinatology and Obstetrics and Gynecology (60 papers each). The top 5 most impactful journals in terms of citations per paper are: JAMA - Journal of the American Medical Association (45.52), Acta Obstetricia et Gynecologica Scandinavica

Figure 2: Network Visualization of Top 56 Keywords. 
Table 5: Scientometric Profile of Top 20 organizations in “Covid-19 and Pregnancy” during 2020-21.

\begin{tabular}{|c|c|c|c|c|c|c|c|c|}
\hline S.No. & Name of the Organization & TP & TC & CPP & $\mathrm{HI}$ & ICP & ICP\% & $\mathrm{RCl}$ \\
\hline 2 & Tongji Medical College, China & 64 & 3057 & 44.96 & 23 & 21 & 32.81 & 2.08 \\
\hline 3 & Harvard Medical School, USA & 52 & 440 & 6.47 & 11 & 20 & 38.46 & 0.30 \\
\hline 4 & University of Toronto, Canada & 43 & 670 & 9.85 & 10 & 31 & 72.09 & 0.46 \\
\hline 7 & Monash University, Australia & 38 & 443 & 6.51 & 11 & 24 & 63.16 & 0.30 \\
\hline 8 & Columbia University Irving Medical Center, USA & 38 & 1131 & 16.63 & 9 & 5 & 13.16 & 0.77 \\
\hline 9 & King's College London, U.K. & 37 & 646 & 9.50 & 9 & 15 & 40.54 & 0.44 \\
\hline 10 & Brigham and Women's Hospital, USA & 37 & 397 & 5.84 & 11 & 9 & 24.32 & 0.27 \\
\hline 13 & Massachusetts General Hospital, USA & 35 & 202 & 2.97 & 8 & 12 & 34.29 & 0.14 \\
\hline 14 & Ospedale Maggiore Policlinico Milano, Italy & 34 & 474 & 6.97 & 11 & 9 & 26.47 & 0.32 \\
\hline 15 & Sapienza Università di Roma, Italy & 33 & 608 & 8.94 & 9 & 8 & 24.24 & 0.41 \\
\hline 16 & University College London, U.K. & 31 & 796 & 11.71 & 10 & 11 & 35.48 & 0.54 \\
\hline 17 & St George's, University of London, U.K. & 30 & 763 & 11.22 & 11 & 6 & 20 & 0.52 \\
\hline 18 & University of Health Sciences, Turkey & 30 & 116 & 1.71 & 6 & 2 & 6.67 & 0.08 \\
\hline 19 & Renmin Hospital of Wuhan University, China & 29 & 1522 & 22.38 & 14 & 15 & 51.72 & 1.03 \\
\hline 20 & INSERM, France & 28 & 197 & 2.90 & 7 & 6 & 21.43 & 0.13 \\
\hline
\end{tabular}

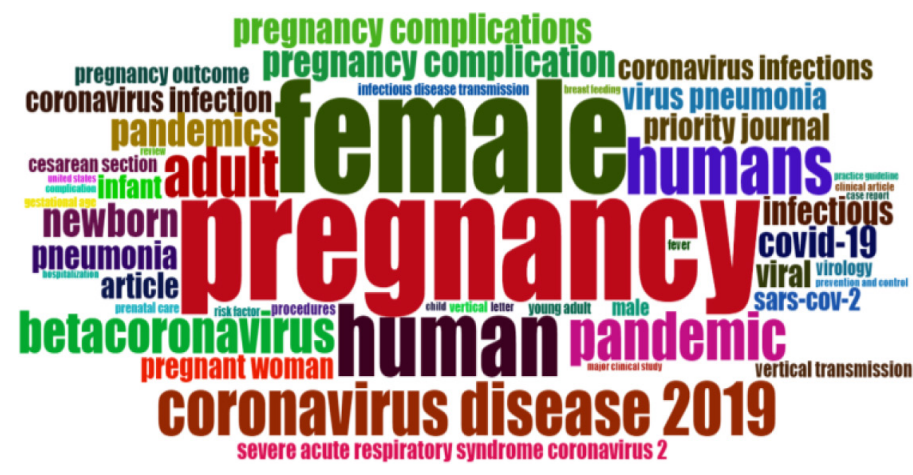

Figure 3: WordCloud of Top 56 Keywords.

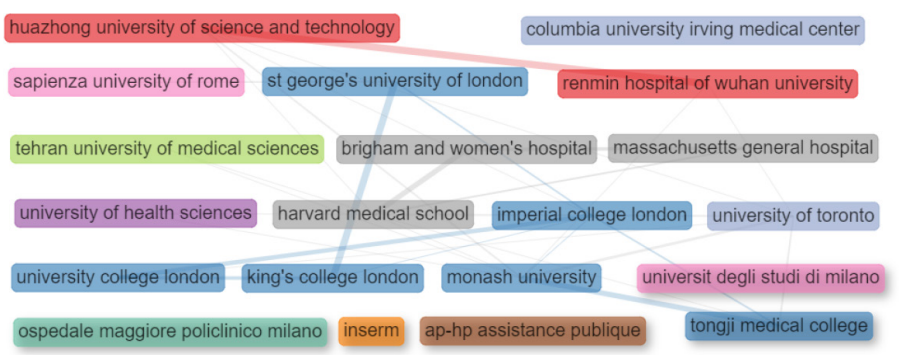

Figure 4: Collaboration Network of top 20 Organizations.

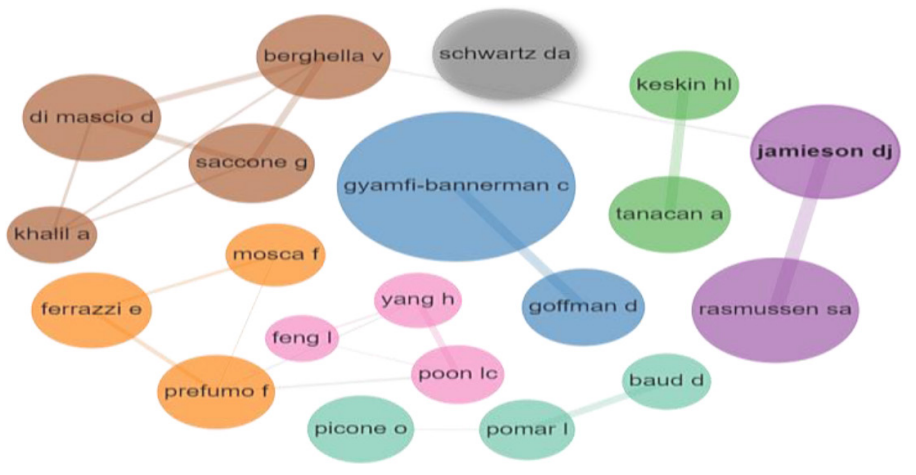

Figure 5: Collaboration Network of Top 20 Authors.

(39.22), Ultrasound in Obstetrics and Gynecology (25.95), American journal of Obstetrics and Gynecology MFM (24.42) and Midwifery (23.57) (Table 8).

\section{High-Cited Papers}

Out of 2945 publications on "Covid-19 and Pregnancy", only 61 (2.07\%) publications were high-cited papers and received 102 to 1571 citations per paper. Together, these 61 high-cited papers received 14620 citations, averaging 239.67 citations per paper. The distribution of 61 high-cited papers is skewed: 38 papers received $102-200$ citations, 19 papers received 201-400 citations, 6 papers 401-603 citations and 1 paper 1571 
Table 6: Collaboration Linkages among Top 20 Organizations in “Covid-19 and Pregnancy” during 2020-21.

\begin{tabular}{|c|c|c|c|}
\hline S.No & Name of the Organization & Collaborative Linkages with other Organizations & TCL (NOO) \\
\hline 1 & Huazhong University of Science and Technology, china & 2(64), 3(1), 4(2), 7(2), 9(1), 11(1), 12(1), 16(1), 19(10) & $83(9)$ \\
\hline 2 & Tongji Medical College, China & 1(64), 3(1), 4(2), 7(2), 9(1), 11(1), 16(1), 19(9) & $81(8)$ \\
\hline 3 & Harvard Medical School, USA & $1(1), 2(1), 4(2), 6(2), 9(1), 10(29), 13(20), 14(2)$ & $58(8)$ \\
\hline 4 & University of Toronto, Canada & 1(2), 2(2), 3(2), 7(4), 10(1), 12(2), 14(1), 16(3), 19(2) & 19(9) \\
\hline 5 & Tehran University of Medical Sciences, Iran & $7(1)$ & $1(1)$ \\
\hline 6 & Università degli Studi di Milano, Italy & $3(2), 14(28), 15(3)$ & $33(3)$ \\
\hline 7 & Monash University, Australia & $1(2), 2(2), 4(4), 11(2), 19(2)$ & $12(5)$ \\
\hline 8 & Columbia University Irving Medical Center, USA & $4(1), 16(1)$ & 2(2) \\
\hline 9 & King's College London, U.K. & $1(1), 2(1), 3(1), 11(2), 13(1), 16(6), 17(12)$ & $24(7)$ \\
\hline 10 & Brigham and Women's Hospital, USA & . Usa3(29), 4(1), 7(1), 11(1), 13(15), 16(1) & $48(6)$ \\
\hline 11 & Imperial College London, U.K. & 1(1), 2(1), 3(1), 7(2), 9(2), 16(7), 17(4) & $18(7)$ \\
\hline 12 & AP-HP Assistance Publique - Hopitaux de Paris, France & $1(1), 4(2), 7(1), 11(1), 20(11)$ & $16(5)$ \\
\hline 13 & Massachusetts General Hospital, USA & $3(20), 9(1), 10(15), 20(1)$ & $37(4)$ \\
\hline 14 & Ospedale Maggiore Policlinico Milano, Italy & $3(2), 4(1), 6(28), 15(2)$ & $33(4)$ \\
\hline 15 & Sapienza Università di Roma, Italy & $6(3), 14(2), 17(3)$ & $8(3)$ \\
\hline 16 & University College London, U.K. & $1(1), 2(1), 3(1), 4(3), 8(1), 9(6), 10(1), 11(7), 14(1)$ & 22(9) \\
\hline 17 & St George's, University of London, U.K. & $6(1), 9(12), 11(4), 14(1), 15(3)$ & $21(5)$ \\
\hline 18 & University of Health Sciences, Turkey & Nil & Nil \\
\hline 19 & Renmin Hospital of Wuhan University, China & $1(10), 2(9), 4(2), 7(2)$ & $23(4)$ \\
\hline 20 & INSERM, France & $12(11)$ & $1(11)$ \\
\hline
\end{tabular}

TCL $(\mathrm{NOO})=$ Total collaborative linkages (Number of organizations)

Table 7: Scientometric Profile of Top 8 Most Productive and Most impactful Organizations each in "Covid-19 and Pregnancy" during $2020-21$.

\begin{tabular}{|c|c|c|c|c|c|c|c|c|c|}
\hline S.No. & Name of the Authors & Affiliation of the Author & TP & TC & CPP & $\mathrm{HI}$ & ICP & ICP\% & $\mathrm{RCl}$ \\
\hline 1 & A. Khalil. & St George’s, University of London, U.K. & 23 & 671 & 29.17 & 9 & 13 & 56.52 & 0.69 \\
\hline 2 & C. Gyamfi-Bannerman. & Columbia University Irving Medical Center, USA & 19 & 618 & 32.53 & 8 & 0 & 0 & 0.77 \\
\hline 3 & D. Goffman & Columbia University Irving Medical Center, USA & 17 & 1045 & 61.47 & 8 & 0 & 0 & 1.47 \\
\hline 4 & L.C. Poon. & Chinese University of Hong Kong & 17 & 769 & 45.24 & 11 & 15 & 88.24 & 1.07 \\
\hline 5 & D.J. Jamieson & Emory University School of Medicine, USA & 16 & 547 & 34.19 & 7 & 2 & 12.5 & 0.81 \\
\hline 6 & G. Saccone & Università degli Studi di Napoli Federico II, Italy & 16 & 506 & 31.63 & 7 & 7 & 43.75 & 0.75 \\
\hline 7 & D. Baud & Centre Hospitalier Universitaire Vaudois, Switzerland & 15 & 450 & 30 & 7 & 8 & 53.33 & 0.71 \\
\hline 8 & V. Berghella & Thomas Jefferson University, USA & 15 & 642 & 42.8 & 9 & 7 & 46.67 & 1.01 \\
\hline 9 & A. Tanacan & T.C. Sağlık Bakanlığı, Turkey & 15 & 57 & 3.8 & 5 & 0 & 0 & 0.09 \\
\hline 10 & S.A. Rasmussen & University of Florida College of Medicine, USA & 14 & 553 & 39.5 & 6 & 2 & 14.29 & 0.93 \\
\hline 11 & E. Ferrazzi & Ospedale Maggiore Policlinico Milano, Italy & 13 & 233 & 17.92 & 5 & 2 & 15.38 & 0.42 \\
\hline 12 & H.L. Keskin & T.C. Sağlık Bakanlığı,, Turkey & 13 & 62 & 4.77 & 5 & 0 & 0 & 0.11 \\
\hline 13 & F. Prefumo & Università degli Studi di Brescia, Italy & 13 & 319 & 24.54 & 7 & 3 & 23.08 & 0.58 \\
\hline 14 & L. Pomar & Centre Hospitalier Universitaire Vaudois, Switzerland & 12 & 389 & 32.42 & 5 & 7 & 58.33 & 0.77 \\
\hline 15 & H. Yang & Peking University First Hospital, China & 12 & 2369 & 197.42 & 9 & 9 & 75 & 4.66 \\
\hline 16 & D. Di Mascio & Sapienza Università di Roma, Italy & 11 & 452 & 41.09 & 5 & 6 & 54.55 & 0.97 \\
\hline 17 & L. Feng & Tongji Medical College, China & 11 & 1164 & 105.82 & 9 & 3 & 27.27 & 2.5 \\
\hline 18 & F. Mosca & Università degli Studi di Milano, Italy & 11 & 264 & 24 & 6 & 5 & 45.45 & 0.57 \\
\hline 19 & O. Picone. & Hopital Louis-Mourier & 11 & 143 & 13 & 5 & 2 & 18.18 & 0.31 \\
\hline \multirow[t]{2}{*}{20} & D.AQ. Schwartz & Medical College of Georgia, USA & 11 & 823 & 74.82 & 8 & 5 & 45.45 & 1.77 \\
\hline & & & 285 & 12076 & 42.37 & & & & \\
\hline
\end{tabular}


Table 8: Profile of Top 20 Journals in "Covid-19 and Pregnancy" during 2020-21.

\begin{tabular}{|c|c|c|c|c|}
\hline S.No & Name of the Journal & TP & TC & CPP \\
\hline 1 & $\begin{array}{l}\text { American Journal of Obstetrics and } \\
\text { Gynecology }\end{array}$ & 94 & 2190 & 23.30 \\
\hline 2 & $\begin{array}{l}\text { International Journal of Gynecology and } \\
\text { Obstetrics }\end{array}$ & 85 & 915 & 10.76 \\
\hline 3 & $\begin{array}{l}\text { European Journal of Obstetrics and } \\
\text { Gynecology and Reproductive Biology }\end{array}$ & 66 & 428 & 6.48 \\
\hline 4 & American Journal of Perinatology & 60 & 843 & 14.05 \\
\hline 5 & Obstetrics and Gynecology & 60 & 639 & 10.65 \\
\hline 6 & $\begin{array}{l}\text { American journal of obstetrics and } \\
\text { gynecology MFM }\end{array}$ & 57 & 1392 & 24.42 \\
\hline 7 & $\begin{array}{l}\text { Journal of Maternal-Fetal and Neonatal } \\
\text { Medicine }\end{array}$ & 48 & 395 & 8.23 \\
\hline 8 & Journal of Perinatal Medicine & 45 & 155 & 3.44 \\
\hline 9 & $\begin{array}{l}\text { BJOG: An International Journal of } \\
\text { Obstetrics and Gynaecology }\end{array}$ & 43 & 523 & 12.16 \\
\hline 10 & Ultrasound in Obstetrics and Gynecology & 37 & 960 & 25.95 \\
\hline 11 & $\begin{array}{l}\text { International Journal of Environmental } \\
\text { Research and Public Health }\end{array}$ & 34 & 79 & 2.32 \\
\hline 12 & $\begin{array}{l}\text { JAMA - Journal of the American Medical } \\
\text { Association }\end{array}$ & 33 & 1502 & 45.52 \\
\hline 13 & BMC Pregnancy and Childbirth & 31 & 64 & 2.06 \\
\hline 14 & PLoS ONE & 26 & 232 & 8.92 \\
\hline 15 & The Lancet Global Health & 25 & 435 & 17.40 \\
\hline 16 & $\begin{array}{l}\text { Journal of Obstetrics and Gynaecology } \\
\text { Research }\end{array}$ & 24 & 44 & 1.83 \\
\hline 17 & $\begin{array}{l}\text { Acta Obstetricia et Gynecologica } \\
\text { Scandinavica }\end{array}$ & 23 & 787 & 34.22 \\
\hline 18 & Journal of Medical Virology & 23 & 304 & 13.22 \\
\hline 19 & Midwifery & 21 & 51 & 2.43 \\
\hline \multirow[t]{3}{*}{20} & The BMJ & 21 & 495 & 23.57 \\
\hline & Total of 20 journals & 856 & 12433 & 14.52 \\
\hline & Global total & 1616 & & \\
\hline
\end{tabular}

citations. Of 61 high-cited papers, 36 were published as articles, 11 as reviews, 8 as letters, 3 as notes, 2 as short survey and 1 as editorial.

Of the 61 high-cited papers, 18 were contributed by one single organization and rest by two or multiple organizations per paper. The 61 high-cited papers involved 153 authors and 116 organizations. Tongji Medical College, China and Huazhong University of Science and Technology, China each contributed 12 high-cited papers, followed by Wuhan University, China, Remin Hospital of Wuhan University, China and Zhonghan Hospital of Wuhan University, China (5 each) etc. These 61 highly cited papers appeared in 43 journals, of which 6 each appeared in American Journal of Obstetrics and Gynecology and American Journal of Obstetrics and Gynecology MFM and 4 appeared in JAMA-Journal of the American Medical Association.

\section{SUMMARY}

The study evaluates global research on "Covid-19 and Pregnancy" using various qualitative and quantitative indicators. The data was retrieved from Scopus database for the period 2020-21. The global research on "Covid-19 and Pregnancy" comprised 2945 publications. These 2945 publications received 31342 citations, registering 10.64 citations per paper. Only $14.26 \%$ (420) publications received funding support from more than 100 agencies, and these funded papers together received 6294 citations averaging to 14.99 citations per paper. Only 2.07\% (61 publications) share of 2945 publications reported high-citations above 100, between 102 to 1571 citations per paper.

In all, 114 countries participated in "Covid-19 and Pregnancy" with top 10 countries contributing $92.43 \%$ global publication share and more than $10 \%$ global citation share. Among top 12 countries, USA, UK and China led in global publications share $(28.96 \%, 11.27 \%$ and $9.3 \%)$ and China (37.30 and 3.51) and USA (12.87 and 1.21) were most impactful countries. International collaborative share in global output varied from $15.96 \%$ to $64.71 \%$. Medicine accounted for the largest share $(91.88 \%)$ in global output on "Covid-19 and Pregnancy", followed by Biochemistry, Genetics and Molecular Biology (7.03\% share), Nursing (6.21\% share) etc.

The 613 organizations and 953 authors participated in global research on the subject, with top 20 most productive organizations and authors contributing $26.38 \%$ and $9.68 \%$ global publications share and $53.64 \%$ and $38.53 \%$ global citation share. Huazhong University of Science and Technology, China (68 papers), Tongji Medical College, China (64 papers), Harvard Medical School, USA (52 papers), University of Toronto (43 papers) and Tehran University of Medical Sciences (40 papers) were the most productive global organizations and Huazhong University of Science and Technology, China (45.88 and 2.12), Tongji Medical College, China (44.96 and 2.08), University of Health Sciences, Turkey (22.38 and 1.03), Columbia University Irving Medical centre (16.63 and 0.77) and University College London (11.71 and 0.54) were the most impactful organizations registering high citation impact and relative citation index. A. Khalil (23 papers), C. Gyamfi-Bannerman (19 papers), D. Goffman and L.C. Poon (17 papers each) and D.J. Jamieson (16 papers) were the most productive authors and H. Yang (197.4 and 4.66), L. Feng (105.12 and 2.5), D.A. Schwartz (74.82 and 1.77), D. Goffman (61.47 and 1.47) L.C. and Poon (45.24 and 1.07) were the most impactful authors.

American Journal of Obstetrics and Gynecology (94 papers), International Journal of Obstetrics and Gynecology (85 papers), European Journal of Obstetrics and Gynecology and Reproductive Biology (66 papers), American Journal of Perinatology and Obstetrics and Gynecology (60 papers each) were the most productive journals in global research on "Covid-19 and Pregnancy". JAMA-Journal of the American Medical Association (45.52), Acta Obstetricia et Gynecologica Scandinavica (34.22), Ultrasound in Obstetrics and Gynecology (25.95), American Journal of Obstetrics and Gynecology MFM (24.42) and Midwifery (23.57) were leading most impactful journals. The 61 (2.07\%) out of 2945 global publications on "Covid-19 and Pregnancy" registered 102 to 1571 citations per paper and they together received 14620 citations averaging 239.67 citations per paper. These 61 publications are assumed as high-cited publications and involve 153 authors, 116 organizations and published in 43 journals.

\section{CONFLICT OF INTEREST}

The authors declare that there is no conflict of interest.

\section{REFERENCES}

1. WHO. Coronavirus Disease (COVID-19) pandemic 2019. Available from: https:// www.who.int/emergencies/diseases/novel-coronavirus-2019/questions-andanswers-hub/q-q-detail/coronavirus-disease-covid-19 [cited 9/10/2021].

2. Dashraath Pradip, Wong Jing Lin Jeslyn, Lim Mei Xian Karen, Lim Li Min, Li Sarah, Biswas Arijit, Choolani Mahesh, Mattar Citra, Su Lin Lin. Coronavirus disease 2019 (COVID-19) pandemic and pregnancy. Am J Obstet Gynecol. Jun 2020;222(6):521-31. doi: 10.1016/j.ajog.2020.03.021, PMID 32217113.

3. Royal College of Obstetricians and Gynaecologists. Coronavirus infection and pregnancy. Available from: https://rcog.org.uk/en/guidelines-research-services/ guidelines/coronavirus-pregnancy/covid-19-virus-infection-and-pregnancy/[cited 
9/10/2021].

4. ICMR. National institute for Research in Reproductive health. Guidance for management of pregnant women in Covid-19 pandemic. Available from: https:// icmr.gov.in/pdf/covid/techdoc/Guidance_For_Management_of_Pregnant_Women_in_COVID19_Pandemic_12042020.pdf [cited 9/10/2021].

5. José V, Shabina A, Robert BG, Ramachandran T, Stephen R, Alexey K, et al. JAMA Pediatr. 2021;175(8):817-26. doi: 10.1001/jamapediatrics.2021.1050, PMID 33885740

6. Panda Sunita, O'Malley Deirdre, Barry Paula, Vallejo Nora, Smith Valerie. Women's views and experiences of maternity care during COVID-19 in Ireland: A qualitative descriptive study. Midwifery. 2021;103:103092. doi: 10.1016/j. midw.2021.103092. PMID 34325384.

7. Ruggiero Marta, Somigliana Edgardo, Tassis Beatrice, Li Piani Letizia, Uceda Renteria Sara, Barbara Giussy, Lunghi Giovanna, Pietrasanta Carlo, Ferrazzi Enrico. Clinical relevance of SARS-COV-2 infection in late pregnancy. BMC Pregnancy Childbirth. Dec 2021;21(1):505. doi: 10.1186/s12884-021-03985-1, PMID 34253173.
8. Wu Meiqin, Wang Yaqian, Yan Chonghuai, Zhao Yan. Study on subclinical hypothyroidism in pregnancy: a bibliometric analysis via CiteSpace. J Matern Fetal Neonatal Med. 2020:1-12. doi: 10.1080/14767058.2020.1729731. PMID 32106735.

9. Zhang Yuan, Zhang Tong Chao, Liu Xiaoyan, Zhang Lei, Hong Fanzhen, Lu Ming. Research trends of pregnancy with scarred uterus after cesarean: a bibliometric analysis from 1999 to 2018. J Matern Fetal Neonatal Med. 2020:1-10. doi: 10.1080/14767058.2020.1830368, PMID 33043744.

10. Tantengco Ourlad Alzeus G, De Jesus Federico Cristobal C, Gampoy Eloina Faye S, Ornos Eric David B, Vidal Manuel S, Cagayan Maria Stephanie Fay S alzeus $\mathrm{G}$ [et al.]. Molar pregnancy in the last 50 years: A bibliometric analysis of global research output. Placenta. Sep 2021:112:54-61. doi: 10.1016/. placenta. 2021.07.003, PMID 34274613.

11. Chen Xue-Lian, Chen Zi-Ru, Cao Zhen-Lan, Han K, Tong Ya-Wen, Xiang Xiao-Hui, Hu Chun-Xiu, Cao ZL [et al.]. The 100 most cited articles in ectopic pregnancy: a bibliometric analysis. Springerplus. 2016;5(1):1815. doi: 10.1186/s40064-0163503-8, PMID 27803848

Article History: Received: 12-08-2021; Revised: 19-09-2021; Accepted: 20-10-2021.

Cite this article: Bansal M, Bansal J, Gupta BM, Kumar A. Covid-19 and Pregnancy: A Scientometric Assessment of Global Publications during 2020-21. JYoung Pharm. 2021;13(3) Suppl:s122-s129. 